\title{
Gonadotropin-releasing hormone receptor expression in endometrial stromal sarcomas: an immunohistochemical study
}

\author{
Olaf Reich ${ }^{1}$, Francisco F Nogales ${ }^{2}$ and Sigrid Regauer ${ }^{3}$ \\ ${ }^{1}$ Department of Obstetrics and Gynecology, Medical University of Graz, Austria; ${ }^{2}$ Department of Pathology, \\ University of Granada, Spain and ${ }^{3}$ Institute of Pathology, Medical University of Graz, Austria
}

\begin{abstract}
Gonadotropin-releasing hormone and its receptors have been identified in several human malignancies. We evaluated gonadotropin-releasing hormone receptor expression in $\mathbf{3 0}$ primary and recurrent endometrial stromal sarcomas. Archival formalin-fixed and paraffin-embedded material was analyzed immunohistochemically with antisera to gonadotropin-releasing hormone receptor type I and gonadotropin-releasing hormone receptor type II using the peroxidase-antiperoxidase method. Gonadotropin-releasing hormone receptor types I and II were demonstrated in most primary endometrial stromal sarcomas in varying intensity and percentage (range, 10-100\%). The staining pattern was either diffuse cytoplasmic or granular/vesicular in perinuclear distribution. Recurrences stained stronger than primary tumors. The demonstration of gonadotropin-releasing hormone receptors I and II expression in endometrial stromal sarcomas may be a rationale for a clinical study of gonadotropin-releasing hormone analogs in the treatment of women with endometrial stromal sarcomas. Modern Pathology (2005) 18, 573-576, advance online publication, 29 October 2004; doi:10.1038/modpathol.3800325
\end{abstract}

Keywords: endometrium; stromal sarcoma; $\mathrm{GnRH}$; treatment

Endometrial stromal sarcomas are rare tumors that account for about $0.2 \%$ of all genital tract malignancies. They have been reported in association with exogenous or endogenous hyperestrogenism. ${ }^{1,2}$ Since endometrial stromal sarcomas are estrogensensitive tumors and because most patients are premenopausal women with endometrial stromal sarcomas they undergo bilateral salpingo-oophorectomy for hormonal ablation as primary treatment. ${ }^{3}$ However, estrogens can be produced by extraovarian tissues and/or by residual tumor cells via the enzyme complex aromatase. ${ }^{4}$

Gonadotropin-releasing hormone receptors (GnRH-R) have been demonstrated in approximately $80 \%$ of ovarian and endometrial cancers and $50 \%$ of breast cancers. ${ }^{5,6}$ Furthermore, GnRH agonists have been shown to decrease aromatase expression in adenomyosis, endometriosis and leiomyomas. ${ }^{7}$ The use of GnRH agonists and antagonists is presently under investigation as treatment modality for

Correspondence: Dr O Reich, MD, Department of Obstetrics and Gynecology, Medical University of Graz, Auenbruggerplatz 14, A-8036 Graz, Austria.

E-mail: olaf.reich@meduni-graz.at

Received 10 June 2004; revised and accepted 23 September 2004; published online 29 October 2004 several human malignancies including breast, endometrial and ovarian cancer.

In this study, we analyzed the expression of GnRH-R types I and II in a series of 30 patients with endometrial stromal sarcomas.

\section{Materials and methods}

We studied archival surgical specimens from 30 patients with endometrial stromal sarcomas from our institutions and from the consultation practices of the authors. All tumors were composed of cells resembling normal proliferative-phase endometrial stromal cells, imparting a monotonous pattern. Only occasionally were spindle-shaped cells identified. The small vessels were evenly distributed and resembled endometrial spiral arterioles. Invasion of the myometrium and partly extensive permeation was characteristic. Tumor was also present in lymphovascular spaces. Mitoses were typically below three per 10 high-power fields $(\mathrm{HPF}=$ objective $\times 40)$, but were occasionally as high as 10/10 HPF. Necrosis and significant atypia were absent. Tissue from primary tumors was available for 29 patients. For one patient, only tissues of lymph node metastases were available. Five patients had recurrent endometrial stromal 
sarcomas and three had died of disease. For immunohistochemical analysis, representative 2$\mu \mathrm{m}$-thick sections of the endometrial stromal sarcomas were incubated with guinea-pig antisera to GnRH-R I (1:1000) and GNRH-R II (1:2000) after proteinase pretreatment. The antisera have been preciously characterized ${ }^{8,9}$ and were generously provided by PD Dr Gundker, Department of Obstetrics and Gynecology, Georg-August University of Goettingen, Germany. Negative staining was recorded when $0-10 \%$ of tumor cells reacted with the antibodies. Positive staining results were recorded as $11-20,21-50,51-80$ and more than $80 \%$ of positive tumor cells.

\section{Results}

A total of 22 of 29 primary tumors showed a positive reaction with antiserum to GnRH-R I whereas seven primary tumors showed no reaction (for details see Table 1, Figure 1). The staining was mostly in a diffuse cytoplasmic distribution (Figure 1a). Three primary tumors showed granular/vesicular staining in perinuclear distribution (Table 1, Figure 1b). Positive staining was seen in solid sheets of stromal tumor cells (Figure 1c) as well as in cells arranged in

Table 1 Expression of GnRH-R I in 29 primary endometrial stromal sarcomas

\begin{tabular}{lrr}
\hline & $N$ & $\%$ \\
\hline Staining pattern & & \\
$\quad$ Negative & 7 & 24 \\
Diffuse cytoplasmatic & 19 & 66 \\
Granular/vesicular & 3 & 10 \\
Positive tumor cells & & \\
$0-10 \%$ (negative) & 7 & 24 \\
$11-20 \%$ & 2 & 7 \\
$21-50 \%$ & 7 & 24 \\
$51-80 \%$ & 10 & 35 \\
$81-100 \%$ & 3 & 10 \\
\hline
\end{tabular}
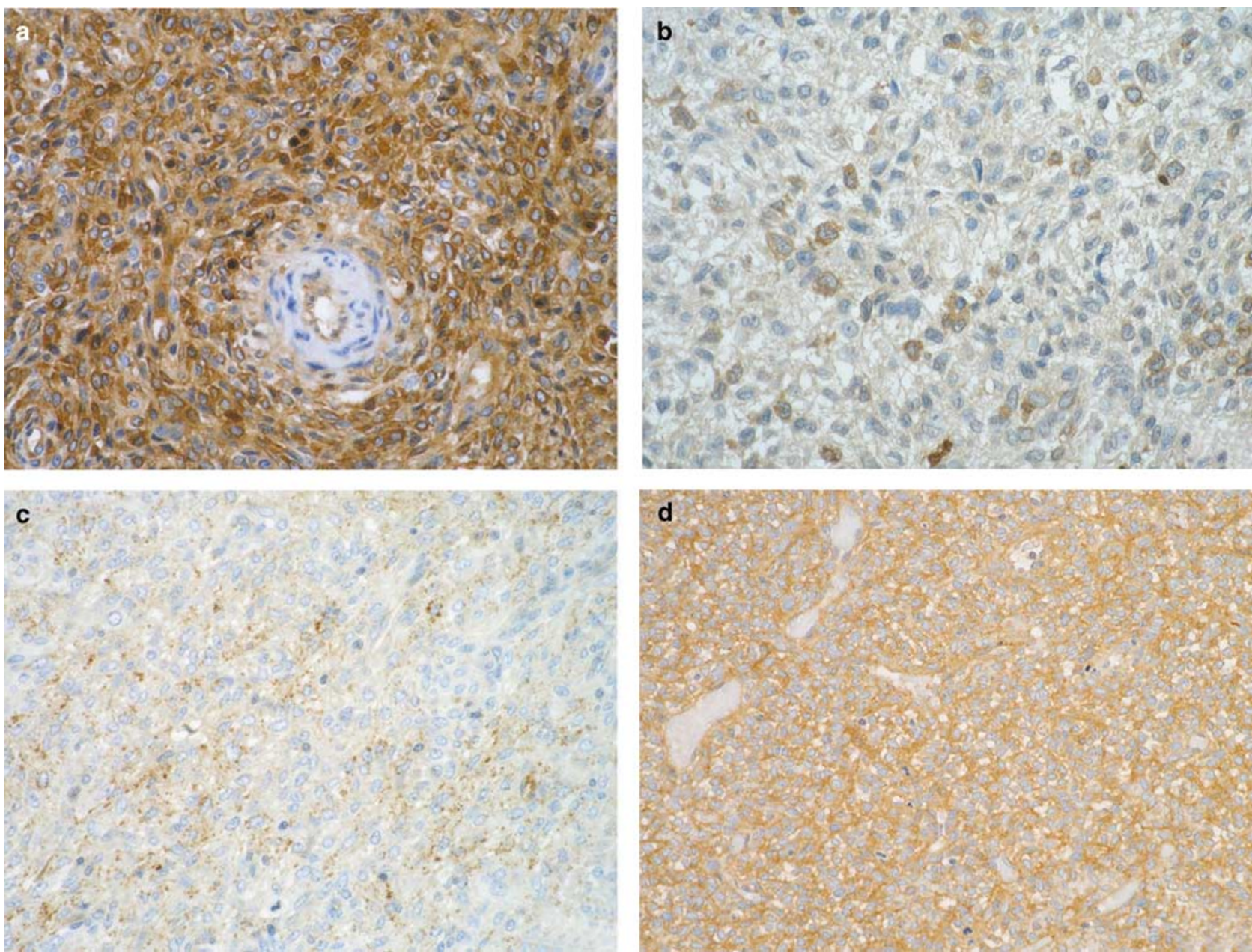

Figure 1 (a) Endometrial stromal sarcoma with diffuse GnRH-R I expression with homogeneous strong cytoplasmic staining in the absence of nuclear staining. (b) Granular/vesicular staining with GnRH-R I. (c) Solid sheets of tumor cells and groups of nested cells demonstrate focal positivity. (d) GnRH-R II is less pronounced. 
Table 2 Expression of GnRH-R I in primary and metastatic/ recurrent endometrial stromal sarcomas

\begin{tabular}{lcl}
\hline & $\begin{array}{c}\text { Primary } \\
\text { endometrial } \\
\text { stromal } \\
\text { sarcoma }\end{array}$ & \\
\hline Pt. 1 & $30 \%$ & $100 \%$ (vagina/urinary bladder) \\
Pt. 2 & $40 \%$ & $70 \%$ (omentum) \\
Pt. 3 & $70 \%$ & $100 \%$ (small intestine) \\
Pt. 4 & $80 \%$ & $100 \%$ (omentum) \\
Pt. 5 & No primary & $100 \%$ (lymph node) \\
& ESS & \\
& available &
\end{tabular}

nests and whorls. The perivascular stromal cells were negative in all tumors. Staining results with GnRH-R II paralleled those of GnRH-R I but expression of GnRH-R II was seen in fewer cells and at a lesser intensity (Figure 1d). The staining patterns for recurrent tumors were similar to those in primary tumors. However, in recurrent endometrial stromal sarcomas, the GnRH-R expression was observed in a higher percentage of tumor cells (see Table 2). The patient for whom only tissue from lymph node recurrence was available for examination had a $100 \%$ positivity with GnRH-R I and II in all lymph node metastases.

\section{Discussion}

Most primary and recurrent endometrial stromal sarcomas in this series expressed receptors for GnRH I and II, and staining was heterogeneous (Table 1, Figure 1a-d).

$\mathrm{GnRH}$ is a key regulator in estrogen biosynthesis and estrogen is a promoting factor in endometrial stromal sarcoma. ${ }^{3,4}$ In stage I endometrial stromal sarcomas, higher recurrence rates are found in women with residual ovarian tissue than in those treated with bilateral oophorectomy. ${ }^{2}$ Similarly, shrinkage of metastases has been reported after bilateral oophorectomy and radiation-induced castration. ${ }^{10,11}$ Krieger and Gusberg ${ }^{12}$ reported a lower incidence of recurrence and longer disease-free survivals after bilateral oophorectomy.

Recurrences develop in one-third to one-half of patients with endometrial stromal sarcomas and can appear as long as 30 years after primary therapy. ${ }^{13,14}$ A growth stimulus by estrogens on residual tumor cells may contribute to recurrence. After oophorectomy, estrogens can be produced by peripherial tissues and/or by aromatase-positive residual tumor cells of endometrial stromal sarcomas. ${ }^{4,15}$

$\mathrm{GnRH}$ exerts its action through its interaction with specific receptors. The known receptors can be broadly divided into two forms, GnRH-R I and GnRH-R II. ${ }^{8,16}$ The number of patients in our study precludes speculation about association between clinical behavior and heterogeneous GnRH-R I and II expression but immunohistochemical detection of the receptors may identify tumor cells with an autocrine regulatory potential based on GnRH. ${ }^{9}$ Interestingly, the five recurrent tumors in our series had high levels of GnRH-R I and II expression.

$\mathrm{GnRH}$ and its agonists have an inhibitory effect on the growth of several hormone-dependent human tumors. ${ }^{6,7,17,18} \mathrm{GnRH}$ agonists are widely used in the systemic treatment of premenopausal women with estrogen-dependent breast cancer, both in the setting of adjuvant treatment of the primary carcinoma and for metastatic disease. ${ }^{19} \mathrm{GnRH}$ agonists have also been used in patients with ovarian cancer and endometrial cancer., ${ }^{6,20,21} \mathrm{GnRH}$ analogs with a cytotoxic agent covalently linked to a GnRH analog have been developed. ${ }^{22}$ Furthermore, GnRH antagonists are used in cancer therapy. ${ }^{6,15}$

The demonstration of GnRH-R I and II expression in endometrial stromal sarcomas may be a rationale for a clinical study of GnRH analogs in the treatment of women with endometrial stromal sarcomas. Anecdotal reports of successful adjuvant hormonal therapy have been published. Mesia and Demopou$\operatorname{los}^{23}$ reported an incomplete regression in one patient with stage I endometrial stromal sarcoma after treatment with the GnRH agonist leuprolide acetate. Scribiner and Walker ${ }^{24}$ reported that a woman with an inoperable endometrial stromal sarcoma was treated with leuprolide acetate, progesterone and aromatase inhibitor resulting in Kursir marked tumor shrikage.

\section{Acknowledgements}

We thank PD Dr C Grundker, Department of Obstetrics and Gynecology, Georg-August University Goettingen, Germany, for kindly providing antiGnRH-R I and anti-GnRH-R II antisera.

\section{References}

1 Press MF, Scully RE. Endometrial sarcomas complicating ovarian thecoma, polycystic ovarian disease and estrogen therapy. Gynecol Oncol 1985;21:135-154.

2 Genazzani AR, Gadducci A, Gambaccini M. Controversial issues in climacteric medicine II: hormone replacement therapy and cancer. Maturitas 2001;40: 117-130.

3 Reich O, Regauer S, Urdl W, et al. Expression of oestrogen and progesterone receptors in low-grade endometrial stromal sarcomas. Br J Cancer 2000;82: 1030-1034.

4 Reich O, Regauer S. Aromatase expression in lowgrade endometrial stromal sarcomas-an immunohistochemical study. Mod Pathol 2004;17:104-108. 
5 Moriya T, Suzuki T, Pilichowska M, et al. Immunohistochemical expression of gonadotropin releasing hormone receptor in human breast carcinoma. Pathol Int 2001;51:333-337.

6 Emons G, Grundker C, Gunthert AR, et al. GnRH antagonists in the treatment of gynecological and breast cancers. Endocrinol Relat Cancer 2003;10: 291-299.

7 Ishihara H, Kitawaki J, Kado N, et al. Gonadotropinreleasing hormone agonist and danazol normalize aromatase cytochrome $P 450$ expression in eutopic endometrium from women with endometriosis, adenomyosis, or leiomyoma. Fertil Steril 2003;79(Suppl 1): 735-742.

8 Grundker C, Gunthert AR, Millar RP, et al. Expression of gonadotropin-releasing hormone II (GnRH-II) receptor in tumor cell proliferation. J Clin Endocrinol Metab 2002;87:1427-1430.

9 Grundker C, Gunthert AR, Westphalen S, et al. Biology of the gonadotropin-releasing hormone system in gynecological cancers. Eur J Endocrinol 2002;146: 1-14.

10 Baggish MS, Woodruff JD. Uterine stromatosis: clinicopathologic features and hormone dependency. Obstet Gynecol 1972;40:487-498.

11 Gloor E, Schneyder P, Cikes M, et al. Endolymphatic stromal myosis. Surgical and hormonal treatment of extensive abdominal recurrence 20 years after hysterectomy. Cancer 1982;50:1888-1893.

12 Krieger PD, Gusberg SB. Endolymphatic stromal myosis-a grade I endometrial sarcoma. Gynecol Oncol 1973;1:299-313.

13 Styron SL, Burke TW, Linville WK. Low-grade endometrial stromal sarcoma recurring over three decades. Gynecol Oncol 1989;35:275-278.

14 Chang KL, Crabtree GS, Lim-Tan SK, et al. Primary uterine endometrial stromal neoplasms-a clinico- pathologic study of 117 cases. Am J Surg Pathol 1990;14:415-438.

15 Sasano H, Harada N. Intratumoral aromatase in human breast, endometrial, and ovarian malignancies. Endocrinol Rev 1998;19:593-607.

16 Chemgalvala MV, Pelletier JC, Kopf GS. GnRH agonists and antagonists in cancer therapy. Curr Med Chem Anti-Cancer Agents 2003;3:399-410.

17 Imai A, Ohno T, Iida K, et al. Presence of gonadotropin-releasing hormone receptor and its messenger ribonucleic acid in endometrial carcinoma and endometrium. Gynecol Oncol 1994;55:144-148.

$18 \mathrm{Kim}$ JW, Lee YS, Kim BK, et al. Cell cycle arrest in endometrial carcinoma cells exposed to gonadotropinreleasing hormone analog. Gynecol Oncol 1999;73: 368-371.

19 Jonat W. The role of LHRH analogs in premenopausal breast cancer. In: Lunenfeld B (ed). GnRH Analogs, The State of the Art 2001. Panthenon Publishing Group: New York, 2001, pp 127-134.

20 Kang SK, Choi KC, Yang HS, et al. Potential role of gonadotropin-releasing hormone GnRH-I and GnRH-II in the ovary and ovarian cancer. Endocrinol Relat Cancer 2003;10:169-177.

21 Noci I, Borri P, Nofirraro G, et al. Longstanding survival without cancer progression in a patient affected by endometrial carcinoma treated primarily with leuprolide. Br J Cancer 2001;85:333-336.

22 Schally AV, Nagy A. Cancer chemotherapy based on targeting of cytotixic peptide conjugates to their receptors on tumors. Eur J Endocrinol 1999;141:1-14.

23 Mesia AF, Demopoulos RI. Effects of leuprolide acetate in low-grade endometrial stromal sarcoma. Am J Obstet Gynecol 2000;182:1140-1141.

24 Scribiner DR, Walker H. Low-grade endometrial stromal sacroma preoperative treatment with Depo-Lupron and Mecane. Gynecol Oncol 1998;71:458-460. 